\title{
Assessment of DNA Damage by RAPD in Paracentrotus lividus Embryos Exposed to Amniotic Fluid from Residents Living Close to Waste Landfill Sites
}

\author{
Maurizio Guida, ${ }^{1}$ Marco Guida, ${ }^{2}$ Bruna De Felice, ${ }^{3}$ Daniela Santafede, ${ }^{2}$ \\ Raffaella D'Alessandro, ${ }^{3}$ Attilio Di Spiezio Sardo, ${ }^{1}$ Marianna Scognamiglio, ${ }^{1}$ \\ Cinzia Ferrara, ${ }^{1}$ Giuseppe Bifulco, ${ }^{1}$ and Carmine Nappi ${ }^{1}$ \\ ${ }^{1}$ Department of Obstetric Gynecology Urological Sciences and Reproductive Medicine, University of Naples Federico II, \\ Via Pansini, 80131 Napoli, Italy \\ ${ }^{2}$ Department of Biological Sciences, University of Naples Federico II, Via Mezzocannone 16, 80134 Napoli, Italy \\ ${ }^{3}$ Department of Life Sciences, University of Naples II, Via Vivaldi 43, 81100 Caserta, Italy
}

Correspondence should be addressed to Bruna De Felice, bruna.defelice@unina2.it

Received 4 February 2010; Revised 15 April 2010; Accepted 15 June 2010

Academic Editor: Brad Upham

Copyright ( $) 2010$ Maurizio Guida et al. This is an open access article distributed under the Creative Commons Attribution License, which permits unrestricted use, distribution, and reproduction in any medium, provided the original work is properly cited.

The aim of this study was to assess the genotoxic effects of environmental chemicals on residents living near landfills. The study was based on samples of amniotic fluid from women living in the intensely polluted areas around the Campania region of Italy compared to a nonexposed control group. We evaluated the genetic effects that this amniotic fluids collected in contaminated sites had on Paracentrotus lividus embryos. DNA damage was detected through changes in RAPD (Random Amplified Polymorphism DNA) profiles. The absence of the amplified DNA fragments indicated deletions in Paracentrotus lividus DNA exposed to the contaminated amniotic fluids when compared to equal exposure to uncontaminated fluids. These results show the ability of RAPDPCR to detect and isolate DNA sequences representing genetic alterations induced in P. lividus embryos. Using this method, we identified two candidate target regions for DNA alterations in the genome of $P$. lividus. Our research indicates that RAPD-PCR in P. lividus embryo DNA can provide a molecular approach for studying DNA damage from pollutants that can impact human health. To our knowledge, this is the first time that assessment of DNA damage in P. lividus embryos has been tested using the RAPD strategy after exposure to amniotic fluid from residents near waste landfill sites.

\section{Introduction}

EUROHAZCON studies have reported a $33 \%$ increase in risk of congenital anomalies, both chromosomal and nonchromosomal, around hazardouswaste landfill sites [1, 2]. Risk was proportional to distance from waste epicenters.

However, hazardous-waste sites in the Campania region of Italy differ in that they are distributed over a wide densely populated area, with an estimated 1230 illegal dump sites in what has been referred to as "The Triangle of Death" [3-6]. This is because, since the 1980s, hazardous-waste dumping has gone on largely uncontrolled. In addition to voluminous amounts of household waste, the region has also been plagued by widespread illegal dumping of toxic industrial chemicals and low-level radioactive waste $[7,8]$. The situation has been aggravated by the ongoing practice of burning rubbish, which in turn creates dioxins and other toxic compounds. Understandably, this overabundant contamination of cropland, water, and air has generated deep concern about its adverse impact on human health and the environment.

In fact, overall mortality, cancer mortality for several causes and congenital anomalies, previously known to be higher than regional averages, have been positively correlated to waste exposure within the area [5]. 
Pregnant women and children living in polluted areas are a high risk group. The risk of exposure to pollution agents may be present in intrauterine life (fetal growth period). The "placental barrier" has been shown to be not entirely sufficient to prevent chemical compounds such as thalidomide and dietilstilbestrol [9]. Aside for pharmaceuticals, lipophilic chemical contaminants such as polycyclic aromatic hydrocarbons (found in cigarette smoke), organic mercury compounds (methylmercury), and ethyl alcohol can easily cross the placenta [10]. Some essential processes, such as the central nervous system development, predominantly occur during fetal life and during the first years of life. Fetal vulnerability and the neurotoxicity of some of the aforementioned agents during this period have been extensively documented in cases of fetal alcohol syndrome and in severe neurological disorders observed in Iraqi children who had been exposed to methylmercury during their intrauterine life due to their mothers intake of bread contaminated with mercury fungicides in the 1970s [11].

Several data about the relation between the living in a polluted environment and changes in amniotic fluid are reported [11, 12]. Global contamination by a variety of anthropogenic persistent organic chemicals has resulted in human exposure throughout all phases of development. In particular, detectable concentrations of dioxins and PCBs have been found in amniotic fluid [13]; dioxins typically are released to the air during waste incineration, the burning of fuels to produce power for industrial purposes, and motor vehicle use. Hexachlorocyclohexane and the major and persistent DDT metabolite, $\mathrm{p}, \mathrm{p}^{\prime}$-DDE $(1,1-$ dichloro-2,2-bis(p-chlorophenyl)ethylene), a potent androgen receptor antagonist, were found in amniotic fluid of women undergoing routine amniocentesis in Los Angeles, California [14]; nonpersistent pesticides were found in the amniotic fluid of women referred for amniocentesis in the agricultural San Joaquin Valley, California, and measurement of pesticide metabolites in amniotic fluid is reported as a biomarker of prenatal exposure [15]. Organochlorine levels have been detectable in the amniotic fluid of women from Tenerife Island (Canary Islands, Spain), reflecting intrauterine exposure of human beings to these persistent organic pollutants [16]. Some phthalates such as DEHP (Di(2-ethylhexyl) phthalate) and MEHP (Mono(2ethylhexyl) phthalate) and their metabolites were found in amniotic fluid because of the maternal exposure [17]. Besides, high levels of bisphenol A (BPA) have also been reported in human amniotic fluid and placental tissue [18]. Considering the widespread use of BPA in industrial and consumer products, BPA exposure highlights the potential threat BPA poses to fetal and subsequent adult health.

Moreover, gene-environment interactions are also being examined for a role in the etiology of complex diseases [1921].Through generalized fetal stress or specific biochemical reactions, in utero environmental exposures appear to mediate complex chronic diseases (cardiovascular disease, obesity, diabetes, and asthma) having recognized genetic components $[22,23]$. Recent findings implicate in utero environmental exposures in developmental disorders such as autism [24].

The evolutionary relationship to humans makes the sea urchin, with its many useful properties, a valuable model to study the process of development and help understand human development $[25,26]$. Accordingly, the study of alterations in sea urchin embryos development is a suitable model for detecting the toxicologic and teratogenic activities of compounds such as heavy metals, UV, and chlorin complexes agents, providing a multiple set of toxicological end-points, because they are highly sensitive to physical and chemical environmental modifications [27-31].

In recent years, molecular genetics has provided a number of new methods for genotoxicity measurement such as random amplified polymorphism DNA (RAPD). DNA damage, mutations, and other DNA alternations alter the electrophoresis pattern because of the modification of primer binding sites and/or damage within DNA contained between primer binding sites. These results allow to use this method to detect the genotoxicity of pollutants [3234].

The random amplified polymorphic DNA (RAPD) assay has been shown to detect genotoxin-induced DNA damage. The RAPD assay has been used to assay DNA alterations induced by heavy metal [35], arsenite [36], quinocetone [37], UV, or X-rays [38] and to detect genetic instability in tumors [39]. DNA alterations include DNA damage (e.g., DNA adducts, breaks), mutations (e.g., point mutations and large rearrangements), and other possible changes (e.g., structural distortion) induced by chemical or physical agents following direct and/or indirect interaction with the genomic DNA. The main advantages of the RAPD method lie in its rapidity, applicability to any organism without prior information on the nucleotide sequence, and in the potential detection of DNA damage and mutations.

Findings support the hypothesis that waste-related environmental exposures in "the Triangle of Death" area of the Campania region of Italy produce increased risks of mortality and congenital anomalies [5]. Since a relation between the living in a polluted environment and changes in amniotic fluid is reported [12-18], here we tested the possibility that the levels of pollution in this area adversely affected human amniotic fluids. Therefore, we assessed the embryotoxicity and genetic toxicity of amniotic fluid from women exposed to such environmental pressure in Paracentrotus lividus embryos. This is the first paper about the application of this methodology using amniotic liquid.

Remarkably, we found that so far unidentified substances in the amniotic fluid from exposed women but not in amniotic fluid from unexposed women interfered with the development of sea urchin embryos. These substances are associated with industrial and household waste.

Our research also found that this contaminated amniotic fluid induced DNA damage in the embryos, which we detected using the RAPD technique. Using this method, we identified two candidate target regions for mutations in the genome of $P$. lividus treated with pollutant contaminated amniotic fluids. 


\section{Material and Methods}

2.1. Sampling. Amniotic fluid samples were obtained from 15 patients living in north-east Naples area (Campania, Italy), characterized by atmospheric pollution and intense environmental pressure due to wastes and 15 patients living in a non-polluted area (Avellino, Campania, Italy). The amniotic fluid was obtained at the moment of delivery, 35th36th week of gestation, exclusively in caesarean operation; those who had serious chronic diseases were excluded from the study.

After approval by the local ethics committee of the Department of Obstetrics and Gynecology, University of Naples (Italy), we obtained informed consent from each patient, that allowed the treatment of this fluid for research. In this informed consent, there were also all the information about the places of birth and the residences, possible diseases, and possible previous deliveries of the patient.

2.2. Sea Urchin Bioassays. The toxicity of amniotic fluid samples obtained from patients living in polluted and nonpolluted areas was assessed by sea urchin embryotoxicity and spermiotoxicity bioassays. Sea urchins from the species $P$. lividus were utilized; gametes were obtained, and embryo cultures were run as described previously in $[40,41]$. Controls were conducted as untreated negative controls in natural filtered seawater (FSW) collected offshore from "Stazione Zoologica di Napoli A. Dohrn", 3.5\% salinity, while $\mathrm{K}_{2} \mathrm{Cr}_{2} \mathrm{O}_{7}$ at $25 \mathrm{ppm}$ concentration was used in parallel as positive control (high toxicity). For embryo bioassays, aliquots were laid in six-well $(10 \mathrm{~mL})$ culture plates, and samples were diluted $(1 \% \mathrm{vol} / \mathrm{vol})$ in culture wells. The exposure of embryos $\left(\sim 20-30\right.$ embryos $\left.\times \mathrm{mL}^{-1}\right)$ to polluted and nonpolluted amniotic liquid occurred throughout development from zygote (10 min after fertilization) up to the pluteus larval stage. Cultures were run at $17.5^{\circ} \pm 1^{\circ} \mathrm{C}$ in the dark up to 72 hours after fertilization.

Sperm bioassays were carried out by suspending P. lividus sperms for 1 hour in amniotic liquid and increasing dilutions of amniotic liquid $(1: 100$ and $1: 10)$ in $50 \mathrm{~mL}$ polystyrene cups. Sperms were suspended in amniotic liquid, as a $0.2 \%$ suspension of concentrated sperm pellet for 2 hours. After exposure, $0.5 \%$ supernatant sperms were used to inseminate untreated egg suspensions $(\sim 50$ eggs $/ \mathrm{mL})$. Changes in the fertilization rate ( $\mathrm{FR}=\%$ fertilized eggs) of exposed sperms were determined by scoring the percent of fertilized eggs in live cleaving embryos (1 to 3 hours postfertilization).

Tests were run in six separate experiments. The observations of larvae were performed on the first 100 pluteus larvae scored in each replicate culture, approximately 72 hours after fertilization, and immobilized in $10^{-4} \mathrm{M}$ chromium sulfate $5 \mathrm{~min}$ prior to observation. The following outcomes in embryogenesis were evaluated [42]: (i) pathologic (P1), malformed plutei, (ii) pathologic embryos (P2), arrested at blastula/gastrula stages and unable to differentiate up to the pluteus stage, and (iii) dead (D) embryos/larvae. The total percentages of P1 and P2 were scored as \% developmental defects (DD). Observations were carried out blind by trained readers, each one evaluating a complete set of cultures.
2.3. Statistical Analysis. Differences in the distributions of actual frequencies observed for each larval class $(\mathrm{N}, \mathrm{P} 1, \mathrm{P} 2$ and $\mathrm{D}$ ) between controls and experimental groups or among experimental groups were tested for significance by the $G$ test (adapted from the log-likelihood ratio test) for $2 \times$ $k$ contingency tables. Differences among the data concerning a single class of developmental defects in control batch and animals exposed to increasing dilutions of the sample $(1: 10$, $1: 100)$ were tested for significance using one-way analysis of variance, followed by the Tukey multiple comparison test [42]. All results shown are mean \pm SE of six separate experiments. The significance level of statistical analyses was set at $P=.05$.

2.4. DNA Extraction and RAPD Analysis. The DNA was extracted separately by phenol-chloroform from each of the replicates from non-polluted amniotic liquid and polluted amniotic liquid-exposed sea urchin embryos.

A negative control (RAPD assay without DNA) was performed to check for no spurious amplification (data not shown).

The integrity of extracted genomic DNA was checked by electrophoresis in $1 \%$ agarose gels.

Sets of 20 OPU, OPE, OPC, and OPA oligonucleotide random 10-mer primers were purchased from Operon Technologies (Alameda, CA). Briefly, the RAPD reaction was performed with $20 \mathrm{ng}$ DNA template in a total volume of $25 \mu \mathrm{L}$ containing $2.5 \mu \mathrm{L}$ of $10 \mathrm{x}$ enzyme assay buffer, $100 \mu \mathrm{M}$ each of dATP, dCTP, dGTP, and dTTP, $2 \mathrm{nM}$ of random (10 bp) primer, $1.5 \mathrm{mM} \mathrm{MgCl}_{2}$, and $1.5 \mathrm{U}$ of AmpliTaq DNA polymerase. The amplification was performed in a PerkinElmer Cetus DNA thermal cycler programmed for 45 cycles as follows: 1 st cycle of $1 \mathrm{~min}$ at $94^{\circ} \mathrm{C}, 1 \mathrm{~min}$ at $38^{\circ} \mathrm{C}, 1 \mathrm{~min}$ at $72^{\circ} \mathrm{C}$, followed by a final extension cycle of $15 \mathrm{~min}$ at $72^{\circ} \mathrm{C}$.

Amplification products were resolved electrophoretically on $2 \%$ agarose gels and stained with ethidium bromide. The image was recorded using the Grab-it program (UVP, USA). The amplifications were carried out in duplicate and on different days for each of the primers used.

For accuracy in the comparison of the results, the nonpolluted amniotic liquid exposed DNA extracts and the polluted amniotic liquid exposed DNA extracts were run in the same gel. A $100 \mathrm{bp}$ molecular weight marker (Roche, Germany) was also included in the same gel. The RAPD band patterns produced by the OPU8 and OPU14 primers were recorded by photography and quantified by using Scion Image software (National Institutes of Health, Bethesda, MD, USA).

2.5. Cloning and Sequencing of RAPD Loci. Amplified fragments were excised from the agarose gel, and DNA was eluted. The eluted DNA was reamplified with the same random primer and using the same concentrations of reaction mixture constituents and PCR cycles conditions as described above. The reamplified DNA fragments were cloned using the TA cloning kit (Invitrogen, Carlsbad, CA), according to the protocol provided by the manufacturer. The presence of the correct insert was confirmed by hybridization 


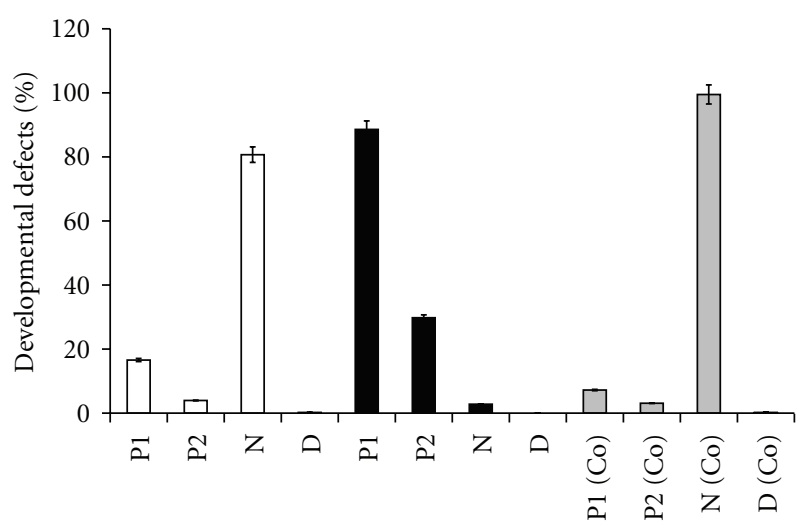

Embryotoxicity assay in P.lividus

Figure 1: Comparison of developmental defects and mortality in $P$. lividus embryos following exposure over the range of zygote to pluteus stage. The gray bar represents the untreated negative control $\left(\mathrm{C}_{0}\right)$. Unpolluted and polluted amniotic liquid-induced developmental defects are represented, respectively, by white and black bars. P1, per cent larval malformations; P2, per cent developmental arrest at blastula/gastrula stage; D, per cent embryonic mortality, $\mathrm{N}$, normal larvae. Results are expressed as means \pm SE from six separate experiments.

with the RAPD-eluted DNA fragment. The cloned RAPDPCR product was sequenced using an ABI DNA Sequencer model 373 (Applied Biosystems) and the Taq DyeDeoxy Terminator Cycle Sequencing kit (Applied Biosystems). Sequences obtained from our clones were compared with known sequences in the GeneBank database using the BLASTn and BLASTx programs.

\section{Results}

3.1. Toxicity Assessment in Paracentrotus lividus by Embryotoxicity and Spermiotoxicity Assays Embryotoxicity. The mean percentage of embryotoxicity (including all 15 samples run in six replicates) is shown in Figure 1. The developmental defects in polluted amniotic liquid-treated P. lividus larvae are mainly of the P1 type (larvae affected in skeletal or gut differentiation). In a lower number of embryos, the effect becomes drastic, with total arrest at prelarval stadium (P2). In particular, in polluted amniotic fluid samples, we have found the maximum quantity of malformed and dead larvae, which indicates the most severe toxicity class.

On the other hand, developmental defects were not detected significantly when embryotoxicity test was performed in non-polluted amniotic liquid-treated P. lividus (Figure 1).

Spermiotoxicity. Spermiotoxicity was more sensitive than embryotoxicity. Significant effects on fertilization rate (FR) were observed for polluted amniotic liquid-treated sea urchin samples (Figure 2). FR shows a significant decline due to a reduction of the fertilization ability of exposed sperms. Notably, the spermiotoxic effect was complete, thus preventing the assessment of embryo cultures. In

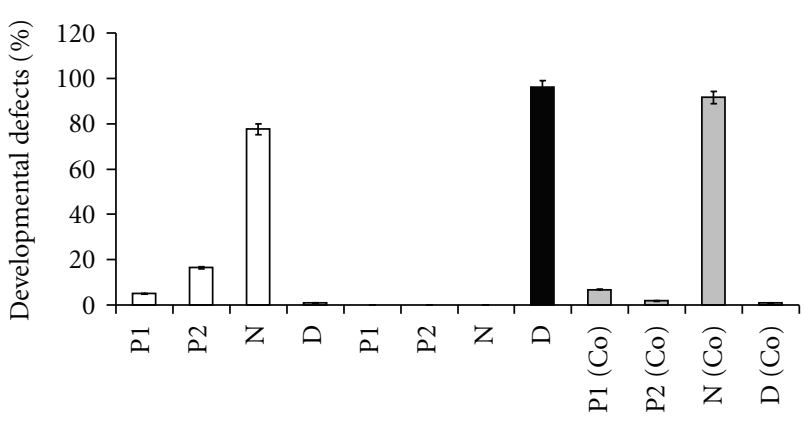

Spermiotoxicity assay in P.lividus

Figure 2: Comparison of developmental defects and mortality in $P$. lividus embryos following exposure to sperms. The gray bar represents the untreated negative control $\left(\mathrm{C}_{0}\right)$. Unpolluted and polluted amniotic liquid-induced developmental defects are represented, respectively, by white and black bars. P1, per cent larval malformations; P2, per cent developmental arrest at blastula/gastrula stage; D, per cent embryonic mortality, N, normal larvae. Results are expressed as means \pm SE from six separate experiments.

non-polluted amniotic liquid-treated P. lividus (Figure 2), significant effects on sperms fertilization rate (FR) were not observed.

3.2. Effect of P. lividus DNA Exposed to Polluted Amniotic Fluid on RAPD Profiles. To analyze instability in the genome of polluted amniotic liquid-treated P. lividus embryos compared to non-polluted amniotic liquid-treated P. lividus embryos using RAPD-PCR fingerprinting, 80 random 10-mer primers were used to amplify genomic DNA samples. RAPD primers generated strong banding patterns in all samples tested. Furthermore, 2 primers, designated OPU8 (5'-GTCCCGACGA- $\left.3^{\prime}\right)$ and OPU14 $\left(\left(5^{\prime}\right.\right.$-ACCGCGAAGG-3'), produced reproducible and the most distinguishable banding profiles between non-polluted and polluted samples after at least five independent RAPD assays, as shown in Figure 3. In contrast, most of the 10mer primers gave band patterns of almost the same profile between non-polluted and polluted samples. We observed similar RAPD-PCR fingerprint in all 15 samples from the contaminated or control area respectively. About $80 \%$ of the specific band of the RAPD pattern was changed by polluted amniotic liquid treatment Among these RAPD bands, four (\#1, \#2, \#3 in the OPU8 primer group and number \#4, in the OPU14 primer group) showed a response in relationship to treatment (Figure 3). Polluted liquid treated sea urchin embryos DNA showed specific losses in the $0.6,0.7,0.9 \mathrm{kbp}$ products amplified with primer OPU8 and in addition, loss of the $0.4 \mathrm{kbp}$ product amplified with primer OPU14 was observed in reactions conducted with polluted amniotic fluid DNA and not with non-polluted amniotic fluid DNA (Figure 3). The gain of fragments $0.2,0.3,1 \mathrm{kbp}$ with OPU8 and $0.2-0.9 \mathrm{kbp}$ with OPU14 was observed in the polluted amniotic fluid DNA as compared to non-polluted amniotic fluid DNA. 


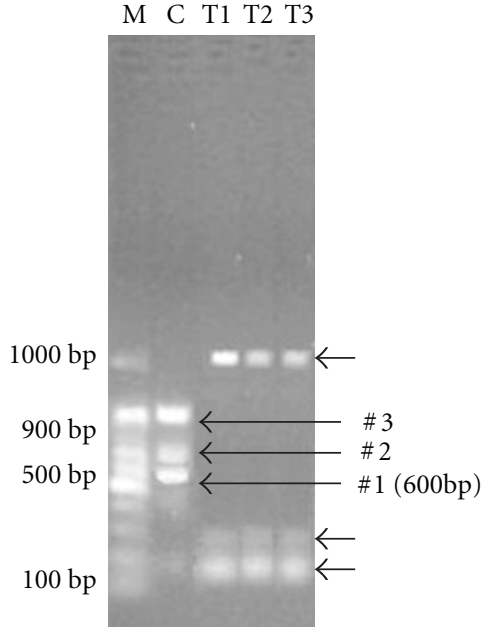

OPU8

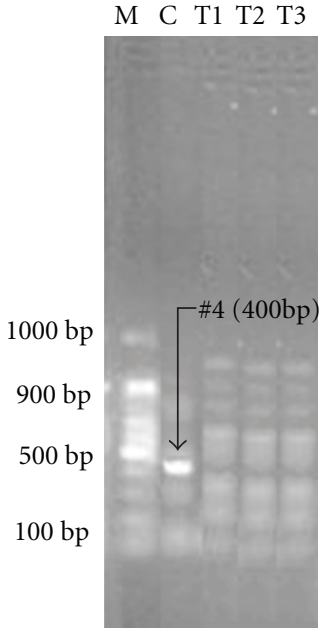

OPU14

(b)
FIGURE 3: Representative RAPD profiles showing DNA fingerprint patterns with DNA from 3 of 15 polluted amniotic liquid-treated $(T)$ and 1 of the 15 non-polluted amniotic liquid-treated sea urchin embryos (C). Arrows indicate gains/losses differences for amplification products and the size of the amplified fragments (bp). Primers used (OPU8 and OPU14) are indicated at the bottom of each set of fingerprints. M, DNA molecular size marker, $100 \mathrm{bp}$ ladder.

3.3. Characterization of Mutated Loci. The $600 \mathrm{bp}$ and the 400 bp RAPD amplification products amplified with primer OPU8 and OPU14, respectively, in the non-polluted amniotic fluid sea urchin embryos DNA were further cloned and sequenced. Sequence homology searches revealed that the 600 bp fragment (band \#1) sequence had significant similarity (98\% identity) with the Strongylocentrotus purpuratus maternal embryonic leucine zipper kinase (XM776674). The 400 bp fragment (band \#4) sequence had significant similarity (100\% identity) with the predicted BMP type II receptor from $S$. purpuratus (XP790983).

\section{Discussion}

The objective of this study was to evaluate possible adverse health effects of amniotic fluid by analyzing genotoxic effect on sea urchin embryos DNA after the exposure to amniotic fluid from pregnant women living in the polluted areas.

To assess the effects of pollutants, tests involving in $P$. lividus embryos (a suitable model for toxicology assays) could be performed, and DNA damage could be assayed by RAPD technique. This method avoids the need of using laboratory animals. Randomly amplified polymorphic DNA PCR (RAPD-PCR) is an assay that could be used to quickly screen exposed cells to pollutants [43-45]. This is the first attempt at a comprehensive analysis of mutations and DNA damage in sea urchin $P$. lividus after pollutants exposure. Here, polluted amniotic liquid exposed $P$. lividus embryos showed $80 \%$ of $\mathrm{P} 1$ malformed larvae in embryotoxicity assay compared to the non-polluted amniotic liquid exposed $P$. lividus embryos (Figure 1). Remarkably, in the spermiotoxicity assay, the offspring of treated sperm (Figure 2) showed dead larvae, probably, because treated sperm could not retain fertilization ability. Interestingly, embryotoxicity and spermiotoxicity assay (Figures 1 and 2) performed using non-polluted amniotic liquid-treated $P$. lividus did not reveal significant developmental malformations.

We found that RAPD polymorphism due to sea urchin DNA exposed to polluted amniotic fluids can be distinguished from the non-polluted amniotic fluids.

Different and distinctive finger pattern were obtained from $P$. lividus embryos DNA under investigation. The two primers used in the sea urchin DNA exposed to polluted amniotic fluids yielded RAPD patterns different from the non-polluted amniotic fluids. This indicated that amniotic fluids from patients living in polluted area created polymorphic regions in the $P$. lividus genome.

The main changes in the RAPD profiles of the present investigation were the appearance or disappearance of different bands and variation in their intensity. These effects might be due to the structural rearrangements in DNA caused by different types of DNA damages. The RAPD method is applicable for the detection of changes in the DNA structure after different genotoxic exposure to pollutants. Thus, the variation in band intensity and disappearance of some bands may correlate with the level of by-products in DNA template after exposure to polluted amniotic fluids, which can change the number of binding sites for Taq polymerase. Appearance of new bands can be explained as a result of different DNA structural changes (breaks, transpositions, deletions, etc.). Thus, the estimate about the existence of mutation and structural alterations in sea urchin DNA after impact of pollutants on the bases of DNA patterns could be obtained after RAPD with a set of primers.

The screening of mutations in P. lividus at a genome-wide level using RAPD-PCR, which is not biased to any particular gene/genomic region, is likely a better approach for drawing conclusions about the mutagenic potential of a pollutant based on sea urchin embryos. Thus, RAPD-PCR could be utilized to detect toxicological and genomic alterations in $P$. lividus exposed to a range of pollutants.

Although RAPD-PCR provides no direct information on the functional importance of the mutated loci, analysis of these genetically altered loci may provide suggestive evidence for loci that participate in the sea urchin damage effects. Cloning and sequencing the amplified loci detected in this study revealed that two of the mutations are in coding region of the genome.

The $400 \mathrm{bp}$ fragment amplified by the OPU14 primer had significant similarity (100\% identity) with the predicted BMP type II receptor from S. purpuratus (XP790983). Bone morphogenetic proteins (BMP) are polypeptide growth factors that regulate cell differentiation and proliferation. BMPs bind to type I and type II serine/threonine kinase receptors to initiate intracellular signaling. It is reported that in sea urchin [46] the BMP signaling pathway is important in mediating communication among cells that regulate cell fate decisions, since morphologies of embryos with changed 
BMP signaling pathway were severely and reproducibly altered. The $600 \mathrm{bp}$ fragment amplified by the OPU8 primer had significant similarity ( $98 \%$ identity) with the predicted Strongylocentrotus purpuratus maternal embryonic leucine zipper kinase (XM776674). Maternal embryonic leucine zipper kinase (MELK) is necessary for proliferation of embryonic and postnatal multipotent neural progenitor proliferation. In our research, the mutation of these genes could support the results obtained by the embryotoxicity assay. Our present findings indicate that novel genes in sea urchin susceptible to mutation as a result of treatment with polluted amniotic fluids can be identified using this RAPD screening method. Further characterization of additional target sites may lead to the identification of additional genes susceptible to mutation and provide clues to the mechanism of $P$. lividus DNA damage treated with polluted amniotic fluids.

In conclusion, for the first time, we assessed the possibility to test embryo-toxicity and genomic changes in Paracentrotus lividus DNA after the exposure to amniotic fluids obtained from pregnant women living in the heavily polluted areas of the Campania region of Italy ("The Triangle of Death"). Residents of these areas have both direct and indirect, through the food chain, daily exposure to polluted soil, water, and air. A larger number of samples, with multicenter pooling, are probably needed to improve the yield of the study done so far. Nevertheless, the use of Paracentrotus lividus has proved to be a useful organism for detecting toxic activity, especially when combined with the RAPD-PCR method for the analysis of mutations in P. lividus exposed to pollutants and toxic compounds.

\section{References}

[1] M. Vrijheid, H. Dolk, B. Armstrong et al., "Chromosomal congenital anomalies and residence near hazardous waste landfill sites," Lancet, vol. 359, no. 9303, pp. 320-322, 2002.

[2] H. Dolk, M. Vrijheid, B. Armstrong et al., "Risk of congenital anomalies near hazardous-waste landfill sites in Europe: the EUROHAZCON study," Lancet, vol. 352, no. 9126, pp. 423427, 1998.

[3] F. Mitis, M. Martuzzi, A. Biggeri, R. Bertollini, and B. Terracini, "Industrial activities in sites at high environmental risk and their impact on the health of the population," International Journal of Occupational and Environmental Health, vol. 11, no. 1, pp. 88-95, 2005.

[4] M. Martuzzi, F. Mitis, A. Biggeri, B. Terracini, and R. Bertollini, "Environment and health status of the population in areas with high risk of environmental crisis in Italy," Epidemiologia e Prevenzione, vol. 26, no. 6, pp. 1-53, 2002.

[5] M. Martuzzi, F. Mitis, F. Bianchi, F. Minichilli, P. Comba, and L. Fazzo, "Cancer mortality and congenital anomalies in a region of Italy with intense environmental pressure due to waste," Occupational and Environmental Medicine, vol. 66, no. 11, pp. 725-732, 2009.

[6] K. Senior and A. Mazza, "Italian "Triangle of death" linked to waste crisis," Lancet Oncology, vol. 5, no. 9, pp. 525-527, 2004.

[7] P. Comba, F. Bianchi, L. Fazzo et al., "Cancer mortality in an area of Campania (Italy) characterized by multiple toxic dumping sites," Annals of the New York Academy of Sciences, vol. 1076, pp. 449-461, 2006.
[8] P. Altavista, S. Belli, F. Bianchi et al., "Cause-specific mortality in an area of Campania with numerous waste disposal sites," Epidemiologia e Prevenzione, vol. 28, no. 6, pp. 311-321, 2004.

[9] R. A. Etzel, S. J. Balk, J. R. Reigart, and P. J. Landrigan, "Environmental health for practicing pediatricians," Indian Pediatrics, vol. 40, no. 9, pp. 853-860, 2003.

[10] L. J. Mazur, "Pediatric environmental health," Current Problems in Pediatric and Adolescent Health Care, vol. 33, no. 1, pp. 6-25, 2003.

[11] J. Grigg, "Environmental toxins; their impact on children's health," Archives of Disease in Childhood, vol. 89, no. 3, pp. 244-250, 2004.

[12] M. L. Carvalho, P. J. Custódio, U. Reus, and A. Prange, "Elemental analysis of human amniotic fluid and placenta by total-reflection X-ray fluorescence and energy-dispersive Xray fluorescence: child weight and maternal age dependence," Spectrochimica Acta Part B, vol. 56, no. 11, pp. 2175-2180, 2001.

[13] W. Foster, S. Chan, L. Platt, and C. Hughes, "Detection of endocrine disrupting chemicals in samples of second trimester human amniotic fluid," Journal of Clinical Endocrinology and Metabolism, vol. 85, no. 8, pp. 2954-2957, 2000.

[14] J. A. Holloway, J. O. Warner, G. H. S. Vance, N. D. Diaper, J. A. Warner, and C. A. Jones, "Detection of house-dust-mite allergen in amniotic fluid and umbilical-cord blood," Lancet, vol. 356, no. 9245, pp. 1900-1902, 2000.

[15] M. J. Silva, J. A. Reidy, A. R. Herbert, J. L. Preau Jr., L. L. Needham, and A. M. Calafat, "Detection of phthalate metabolites in human amniotic fluid," Bulletin of Environmental Contamination and Toxicology, vol. 72, no. 6, pp. 1226-1231, 2004.

[16] A. Bradman, D. B. Barr, B. G. C. Henn, T. Drumheller, C. Curry, and B. Eskenazi, "Measurement of pesticides and other toxicants in amniotic fluid as a potential biomarker of prenatal exposure: a validation study," Environmental Health Perspectives, vol. 111, no. 14, pp. 1779-1782, 2003.

[17] O. P. Luzardo, V. Mahtani, J. M. Troyano et al., "Determinants of organochlorine levels detectable in the amniotic fluid of women from Tenerife Island (Canary Islands, Spain)," Environmental Research, vol. 109, no. 5, pp. 607-613, 2009.

[18] Y. Ikezuki, O. Tsutsumi, Y. Takai, Y. Kamei, and Y. Taketani, "Determination of bisphenol A concentrations in human biological fluids reveals significant early prenatal exposure," Human Reproduction, vol. 17, no. 11, pp. 2839-2841, 2002.

[19] L. A. Criswell, K. G. Saag, T. R. Mikuls et al., "Smoking interacts with genetic risk factors in the development of rheumatoid arthritis among older Caucasian women," Annals of the Rheumatic Diseases, vol. 65, no. 9, pp. 1163-1167, 2006.

[20] A. Van Dellen, H. E. Grote, and A. J. Hannan, "Geneenvironment interactions, neuronal dysfunction and pathological plasticity in Huntington's disease," Clinical and Experimental Pharmacology and Physiology, vol. 32, no. 12, pp. 10071019, 2005.

[21] L. K. Williams, R. A. McPhee, D. R. Ownby et al., "Geneenvironment interactions with CD14 C-260T and their relationship to total serum IgE levels in adults," Journal of Allergy and Clinical Immunology, vol. 118, no. 4, pp. 851-857, 2006.

[22] S. J. Genuis, "The chemical erosion of human health: adverse environmental exposure and in-utero pollution-determinants of congenital disorders and chronic disease," Journal of Perinatal Medicine, vol. 34, no. 3, pp. 185-195, 2006.

[23] F. D. Martinez, "Gene-environment interactions in asthma: with apologies to William of Ockham," Proceedings of the American Thoracic Society, vol. 4, no. 1, pp. 26-31, 2007. 
[24] P. Ashwood, S. Wills, and J. Van de Water, "The immune response in autism: a new frontier for autism research," Journal of Leukocyte Biology, vol. 80, no. 1, pp. 1-15, 2006.

[25] E. Pennisi, "Genetics. Sea urchin genome confirms kinship to humans and other vertebrates," Science, vol. 314, no. 5801, pp. 908-909, 2006.

[26] B. R. Jasny and B. A. Purnell, "The glorious sea urchin," Science, vol. 314, no. 5801, p. 938, 2006.

[27] J. E. Hose, "Potential uses of sea urchin embryos for identifying toxic chemicals: description of a bioassay incorporating cytologic, cytogenetic and embryologic endpoints," Journal of Applied Toxicology, vol. 5, no. 4, pp. 245-254, 1985.

[28] R. Beiras, J. Bellas, N. Fernández, J. I. Lorenzo, and A. Cobelo-García, "Assessment of coastal marine pollution in Galicia (NW Iberian Peninsula); metal concentrations in seawater, sediments and mussels (Mytilus galloprovincialis) versus embryo-larval bioassays using Paracentrotus lividus and Ciona intestinalis," Marine Environmental Research, vol. 56, no. 4, pp. 531-553, 2003.

[29] J. Hunt, G. Birch, M. S. Warne, and R. Krassoi, "Direct toxicity assessment of volatile chlorinated hydrocarbon-contaminated groundwater and derivation of a site-specific guideline," Integrated Environmental Assessment and Management, vol. 5, no. 2, pp. 338-348, 2009.

[30] N. Kobayashi and H. Okamura, "Effects of heavy metals on sea urchin embryo development. 1. Tracing the cause by the effects," Chemosphere, vol. 55, no. 10, pp. 1403-1412, 2004.

[31] H. C. Schröder, G. Di Bella, N. Janipour et al., "DNA damage and developmental defects after exposure to UV and heavy metals in sea urchin cells and embryos compared to other invertebrates," Progress in molecular and subcellular biology, vol. 39, pp. 111-137, 2005.

[32] S. Noel and S. K. Rath, "Randomly amplified polymorphic DNA as a tool for genotoxicity: an assessment," Toxicology and Industrial Health, vol. 22, no. 6, pp. 267-275, 2006.

[33] F. A. Atienzar, P. Venier, A. N. Jha, and M. H. Depledge, "Evaluation of the random amplified polymorphic DNA (RAPD) assay for the detection of DNA damage and mutations," Mutation Research, vol. 521, no. 1-2, pp. 151-163, 2002.

[34] F. A. Atienzar and A. N. Jha, "The random amplified polymorphic DNA (RAPD) assay and related techniques applied to genotoxicity and carcinogenesis studies: a critical review," Mutation Research, vol. 613, no. 2-3, pp. 76-102, 2006.

[35] M. R. Enan, "Application of random amplified polymorphic DNA (RAPD) to detect the genotoxic effect of heavy metals," Biotechnology and Applied Biochemistry, vol. 43, no. 3, pp. 147154, 2006.

[36] Y.-C. Lee, V. C. Yang, and T.-S. Wang, "Use of RAPD to detect sodium arsenite-induced DNA damage in human lymphoblastoid cells," Toxicology, vol. 239, no. 1-2, pp. 108$115,2007$.

[37] X. Jin, Q. Chen, S.-S. Tang et al., "Investigation of quinocetone-induced genotoxicity in HepG2 cells using the comet assay, cytokinesis-block micronucleus test and RAPD analysis," Toxicology in Vitro, vol. 23, no. 7, pp. 1209-1214, 2009.

[38] F. A. Atienzar, B. Cordi, M. E. Donkin, A. J. Evenden, A. N. Jha, and M. H. Depledge, "Comparison of ultraviolet-induced genotoxicity detected by random amplified polymorphic DNA with chlorophyll fluorescence and growth in a marine macroalgae, Palmaria palmata," Aquatic Toxicology, vol. 50, no. $1-2$, pp. 1-12, 2000.
[39] K. P. Singh and D. Roy, "Somatic mutations in stilbene estrogen-induced Syrian hamster kidney tumors identified by DNA fingerprinting," Journal of Carcinogenesis, vol. 3, article no. 4, 2004.

[40] E. De Nicola, S. Meriç, C. Della Rocca et al., "Wastewater toxicity of tannin- versus chromium-based leather tanneries in Marrakesh, Morocco," Archives of Environmental Contamination and Toxicology, vol. 53, no. 3, pp. 321-328, 2007.

[41] G. Pagano, S. Meriç, A. De Biase et al., "Toxicity of bauxite manufacturing by-products in sea urchin embryos," Ecotoxicology and Environmental Safety, vol. 51, no. 1, pp. 28-34, 2002.

[42] G. Pagano, L. G. Korkina, M. Iaccarino, et al., "Developmental, cytogenetic and biochemical effects in sea-urchin bioassais," in Biomarkers in Marine Ecosystems: A Pratical Approach, P. Garrignos, C. H. Walker, H. Barth, and J.-F. Narbonne, Eds., Elsevier, Amsterdam, The Netherlands, 2001.

[43] S. Noel and S. K. Rath, "Randomly amplified polymorphic DNA as a tool for genotoxicity: an assessment," Toxicology and Industrial Health, vol. 22, no. 6, pp. 267-275, 2006.

[44] H. Sh. Weinberg, A. B. Korol, V. M. Kirzhner et al., "Very high mutation rate in offspring of Chernobyl accident liquidators," Proceedings of the Royal Society B, vol. 268, no. 1471, pp. 10011005, 2001.

[45] P. R. Butovskaia, I. A. Martirosian, V. S. Baranov et al., "Detection of somatic mosaicism in humans using polymerase chain reaction with random primers," Genetika, vol. 43, no. 12, pp. 1694-1699, 2007.

[46] L. M. Angerer, D. W. Oleksyn, C. Y. Logan, D. R. McClay, L. Dale, and R. C. Angerer, "A BMP pathway regulates cell fate allocation along the sea urchin animal-vegetal embryonic axis," Development, vol. 127, no. 5, pp. 1105-1114, 2000. 

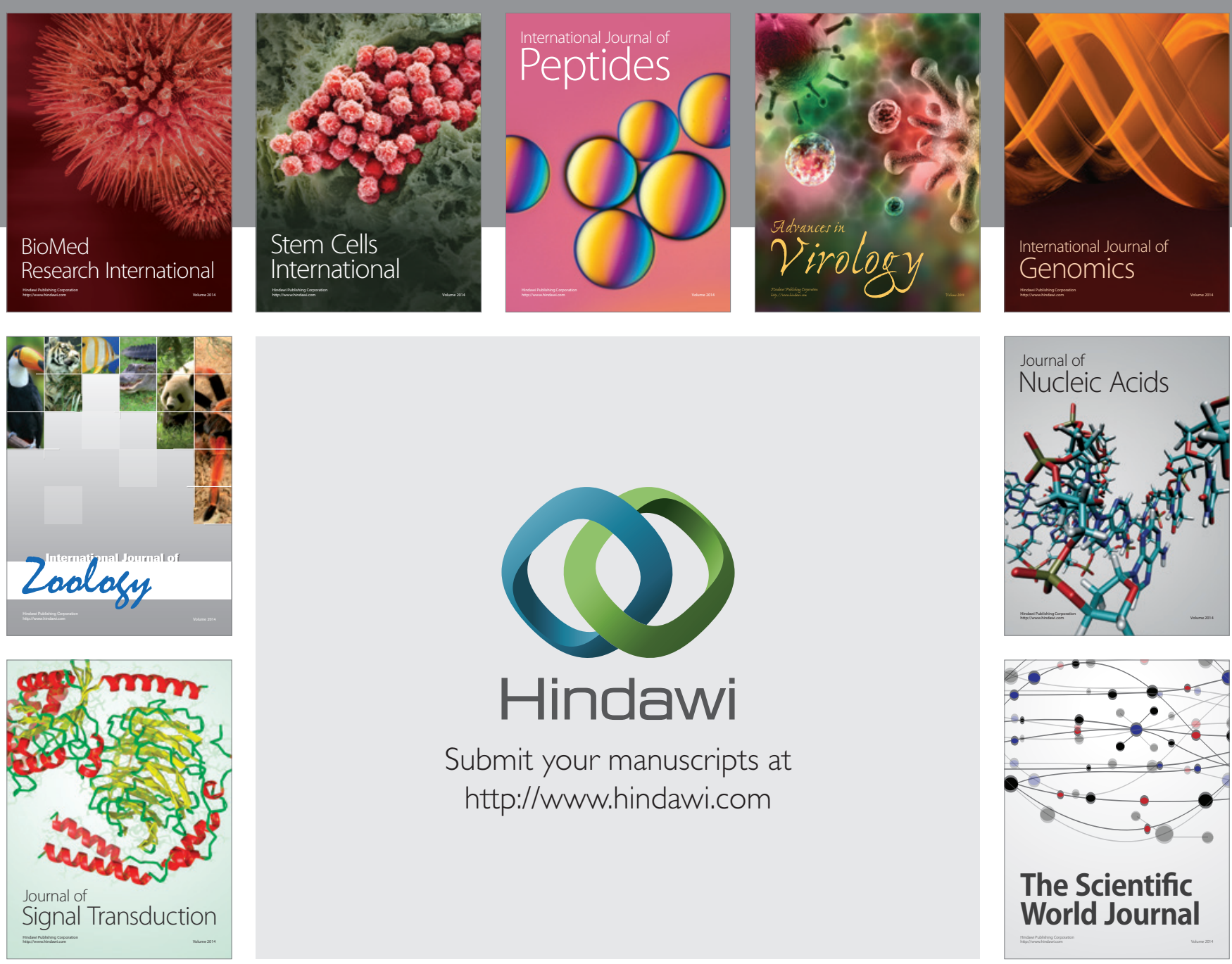

Submit your manuscripts at

http://www.hindawi.com
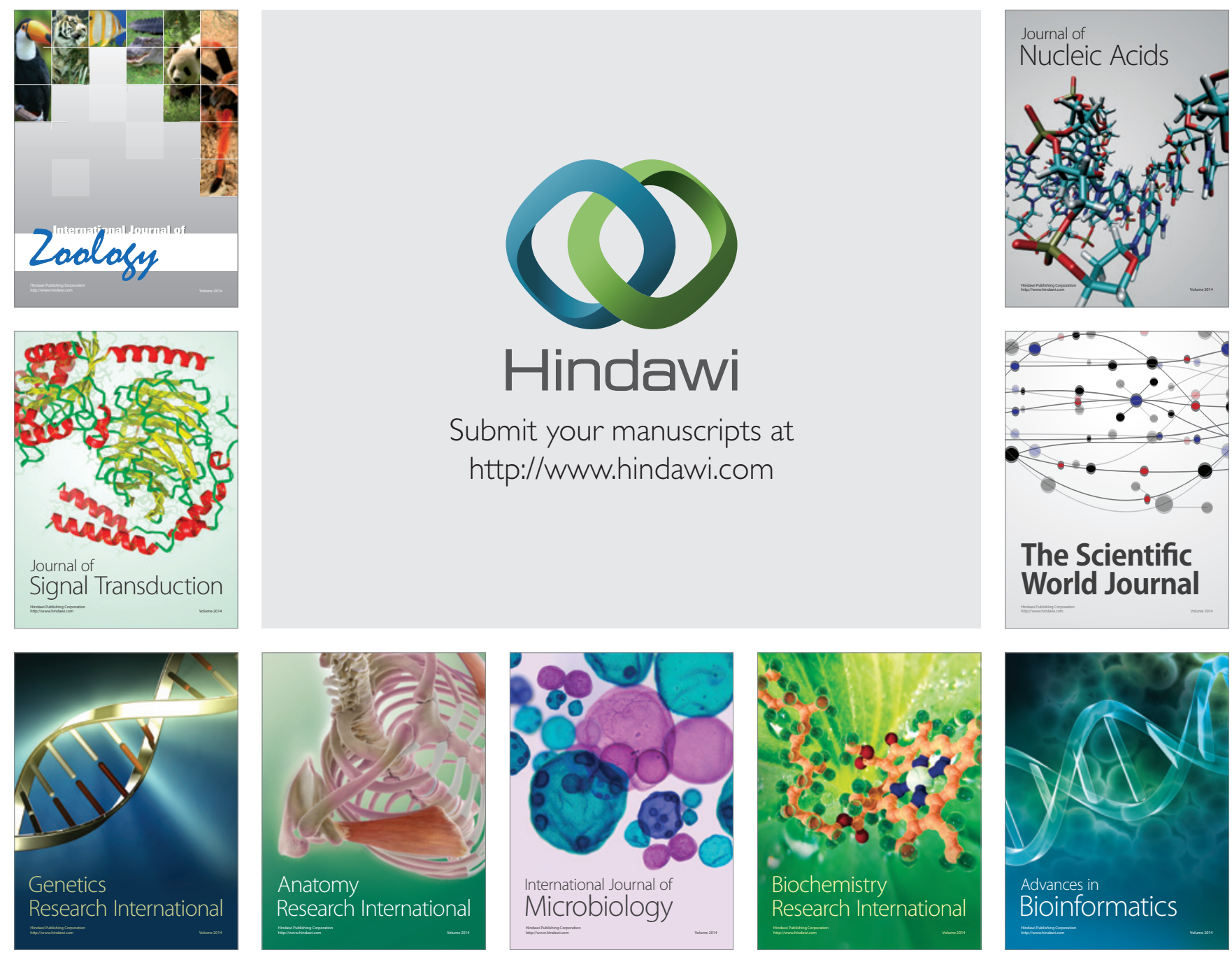

The Scientific World Journal
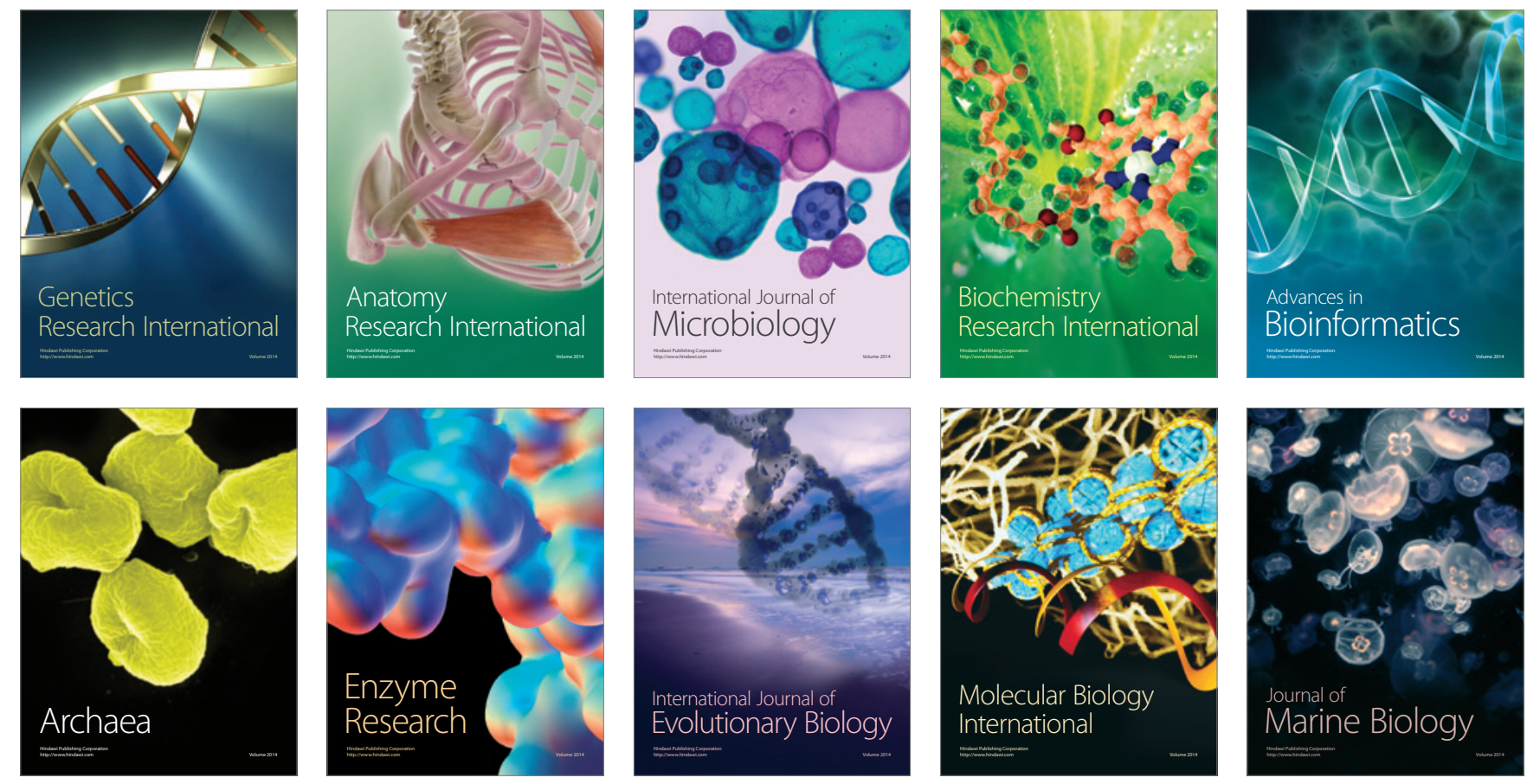